\title{
Motivations for consumption behaviours on the web: a conceptual model based on a holistic approach
}

\author{
Francisco J. Martínez-López* \\ Marketing Department, \\ Universidad de Granada, \\ Campus de Cartuja s/n CP: 18071, Granada, Spain \\ Fax: (0034) 958240695 \\ E-mail: fjmlopez@ugr.es \\ ${ }^{*}$ Corresponding author
}

\section{Paula Luna-Huertas}

Department of Financial Economy and Operations Research, University of Seville, Avda. Ramón y Cajal,

$1 \mathrm{CP}: 41018$ Seville, Spain

Fax: (0034) 954557560 E-mail: pluna@us.es

\section{Francisco José Martínez}

Department of Financial Economy, Accounting and

Operations Research,

University of Huelva, Plaza de la Merced,

11 CP: 21002 Huelva, Spain

Fax: (0034) 959217849 E-mail: francis@uhu.es

\begin{abstract}
The conceptual model presented in this paper poses that there are mainly two types of motivations which determine individuals' consumption behaviour on the web, i.e. utilitarian vs. hedonic. Such motivations, which we call meta-dimensions, group into two clearly differentiated categories of a variety of benefits sought - i.e. dimensions of meta-dimensions - by consumers when navigating the Net. We theoretically analyse a possible relation between both groups of motivations. Furthermore, we consider the influence that they can exert in developing goal-directed and experiential behaviours, that is, behaviours with or without an associated decision problem. Likewise, we also reflect on the role played by the optimum stimulation level and flow state. Finally, we analyse the possible outcome of online consumption experiences taking into account those previous behaviours.
\end{abstract}

Keywords: motivations; consumption; consumer; the web; holistic perspective; conceptual model; theoretical modelling.

Reference to this paper should be made as follows: Martínez-López, F.J., Luna-Huertas, P. and Martínez, F.J. (2006) 'Motivations for consumption behaviours on the web: a conceptual model based on a holistic approach', Int. J. Electronic Marketing and Retailing, Vol. 1, No. 1, pp.3-20. 
Biographical notes: Francisco J. Martínez-López is Lecturer of Marketing at the University of Granada, Spain. He obtained his MSc in Marketing in 2001, and his European $\mathrm{PhD}$ in business administration in 2005 (University of Granada). Among his main areas of interest are consumer behaviour on the internet, consumer behaviour modelling and KDD methodologies for marketing. He has authored chapters of academic books and contributions to international conferences and to international journals like Internet Research, the Irish Journal of Management, Journal of Internet Business, and Fuzzy Economic Review, among others.

Paula Luna-Huertas lectures in Information Systems at the Universidad de Sevilla, Spain. She holds a doctorate in Economic and Business Sciences. She has been a guest lecturer and researcher at several universities (Lyon II, France; Vladivostok, Russia; Santa Fé (Argentina); etc.) and is Director of the ICT research group of the company GITICE. She has taken part in several business research projects at domestic and European levels. She has also worked in a consultancy and training capacity for a number of national and multi-national companies.

Francisco José Martínez is a full-time Professor of the Universidad de Huelva, Spain, lecturing in Information Technology, IT and Information Systems, in the Faculty of Business Sciences. He is a graduate and Doctor in Economic and Business Sciences (with a doctoral prize). He has lectured at several institutions at master and doctorate levels, and has lectured on 30 doctoral courses in various Spanish and American universities. He has been the Director and Chief Researcher for a number of national and international scientific projects and has authored more than a 100 scientific papers. He is currently the Chancellor of the Universidad de Huelva (Spain).

\section{Introduction}

Technological development in electronic communication infrastructures, from their more primitive origins till the more advanced and contemporary forms existing in the present day, has caused an increase in the diversity of contexts where the exchange relations between individuals take place. Moreover, it has been observed how space and time dimensions which have traditionally constrained such exchanges have increasingly been attenuated by communication technologies (Sheth and Sisodia, 1997; Watson et al., 2002).

In this sense, individuals - users of such technological evolutions, thanks to the processes developed to adopt those media advances, have modulated and adapted their own behaviours to the parameters and characteristics defining them. This fact has increasingly stimulated the attention of researchers from different disciplines, such as computer science, marketing, management, sociology, psychology, etc., with the aim of analysing, interpreting and explaining them from their own perspective.

Specifically, the Internet, one of the last stages of the evolution of electronic communication infrastructures, has caused much interest during the last decade. By means of its different applications, the web especially, has played a key role that deserves to be analysed in depth. It has represented such incrementality in communication processes that its rapid diffusion has broadly revolutionised behaviours and conduct patterns of individuals, so their consumption patterns; some refer to this as the 'web effect' (Windham and Orton, 2000). 
We focus our analysis on the exchange relations with a commercial aim on the web. It seems evident both the relevance of and necessity for studying those inherent aspects to consumer behaviour on the internet. This will facilitate the comprehension of their decision processes, as well as their likely mutation when adapting to the electronic markets (see, as e.g., Alba et al., 1997; Peattie and Peters, 1997; Leverick et al., 1997; Hamill and Ennis, 1999; Jones and Vijayasarathy, 1998; John et al., 1999; Jevons and Gabbott, 2000; Reynolds, 2000; Degeratu et al., 2000; Dickson, 2000).

Considering the above, the main objective and scope of this paper is to clarify what their consumption motivations are and the influence that these motivations exert over the development of navigational processes. It is obvious that the study of the consumers' motivations has been always necessary in order to better understand them; this is also true in the web context. However, there are relevant research questions treated in this paper which have not been tackled by previous related research works.

First, consumers' motivations on the web are analysed from a holistic or complete perspective. In other words, consumers' consumption motivation should not only be constrained to the consumers' impulses to shop through the web, but researchers must also consider those other motivations related with experiential behaviours. This significant question has usually been neglected by previous consumers' studies on the web (Wolfinbarger and Gilly, 2001). We firmly believe this kind of analysis to be the most rigorous approach to this research problem: i.e., the online consumption phenomenon should be considered in its entirety. This is not a naïve approach if we take into account that the web presents several specific characteristics which stimulate these kinds of behaviours (Hoffman and Novak, 1996).

Second, we integrate in our model two psychological concepts which are very interesting to complete the explanation of consumption behaviours on the web: the flow state and the optimum stimulation level. Their consideration when analysing consumers' behaviours on the web has been recommended by prior studies (see, as e.g., Hoffman and Novak, 1996; Steenkamp and Burgess, 2002). These elements must be considered to better explain, so understand, the plausible online navigational processes on the web.

All these matters are presented basing on a conceptual model. Though we make use of a theoretical modelling approach for developing our proposals - so they are not empirically tested, the questions and the theoretical relations that we establish are of great interest for fostering the discussion and guiding future research studies interested in the online consumption motivations on the web; either theoretical or empirical.

\section{Structure and main topics}

The structure of this paper is fundamentally defined by the theoretical analysis of a set of elements and relations included in the conceptual model. These elements can be placed in four main stages which are included in the model:

- dimensions

- meta-dimensions of consumption motivations on the web

- the online behaviour trends

- the expected outcome of the navigational process (see Figure 1). ${ }^{1}$ 
Figure 1 Conceptual model

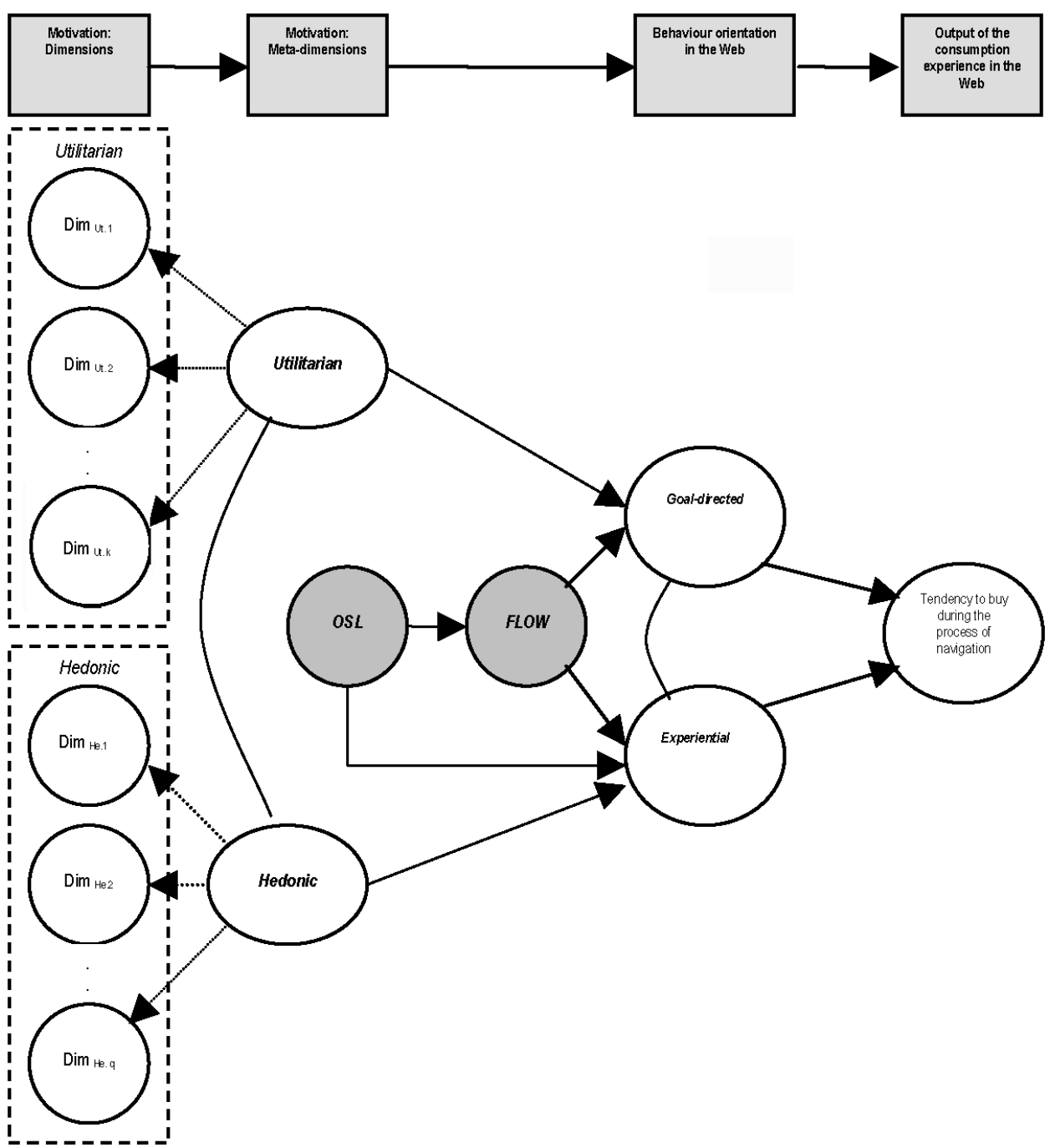

In as much as we are making use of a theoretical modelling methodology (see, as e.g., Lilien et al., 1992; Moorthy, 1993), a set of relations among the elements or concepts considered are put forward by means of propositions, which are theoretically analysed. In the following section, we treat that structure in more detail.

We first distinguish between two main groups of consumers' consumption motivations on the web that we have generically labelled as meta-dimensions. These meta-dimensions comprise a variety of benefits sought by consumers when surfing the web, which we have grouped into utilitarian and hedonic benefits (Childers et al., 2001). However, we have not dealt with those specific benefits in as much detail as it would have been required if an empirical validation of this conceptual model were to be tackled. This task represents a research problem with enough relevance, which goes beyond the objectives of the present paper. For that reason, we have decided to postpone its development to a future research work. In any case, for explanatory purposes, we briefly 
mention some of the main dimensions -i.e., benefits sought-, already considered in previous studies, for the two meta-dimensions.

- Aspects or dimensions related to the utilitarian meta-dimension are better known than that related to the hedonic meta-dimension because they have been analysed in detail in physical markets, as well as in other market contexts closer to electronic markets based on the web; i.e., in-home shopping methods. Some of the most frequently mentioned issues are: convenience, easy access to the existing products and services, time and money savings (Balabanis and Reynolds, 2001; Bhuian, 2001; Donthu and Gilliland, 1996; Ernst and Young, 2000, 2001; Fellenstein and Wood, 2001; Korgaonkar and Wolin, 1999; Meeker and Pearson, 1997; Rohm and Swaminathan, 2004; Rosen and Howard, 2000; Shern and Crawford, 1999).

- On the contrary, dimensional aspects defining the hedonic meta-dimension have received little attention. In this sense, the paper of Wolfinbarger and Gilly (2001) is one of the few that, for the time being, has seriously analysed this question in electronic markets based on the web. These authors developed several focus groups to discover the main dimensions defining consumers' hedonic motivations, so experiential shopping, on the web. The aspects they found were grouped in the following categories:

- surprise, uniqueness and excitement

- positive sociality

- online deal searching

- involvement with a product class.

Second, we analyse the two main types of consumption behaviour that can be developed by consumers on the web - i.e., goal-directed vs. experiential (Hoffman and Novak, 1996) - and their more plausible causes. Attention is paid to the existing relation with utilitarian and hedonic motivations. We theoretically analyse a reasonable concomitance that may exist between the two meta-dimensions of motivation and between the two types of consumption behaviours originated by a possible multi-purpose navigational orientation.

Third, we analyse the expected outcomes of the behaviours. We explicitly focus on the buying tendency during the navigational processes. It is important to remember that this is an aspect of the consumption phenomena that has polarised academics and researchers that study consumer behaviour in electronic markets.

Finally, following the more recent trends of consumer modelling on the web (see, as e.g., Novak et al., 2003; Steenkamp and Burgess, 2002), we theoretically analyse the influence of two related but different kinds of consumers' mental states - flow and the optimum stimulation level - in the development of their navigational processes.

\section{Conceptual model}

Traditional approaches to consumers' behaviour have tended to focus on rational and cognitive aspects, ignoring the also important experiential aspects of consumption. This has resulted in an inability to explain, accurately and completely, the consumption phenomenon. For this reason, a few decades ago the 'information processing 
model' - maybe the most widely accepted approach on which most models of behaviour are based - was strongly criticised. This model is a theory which regards the consumer as a logical and reflective individual concerned in solving decision problems to make purchasing decisions (see one of the seminal papers in experiential consumption: Holbrook and Hirschman, 1982). However, individuals' consumption behaviour is a much broader concept, and it would be a naïve mistake to limit it to purchasing behaviour, though we are aware that the explanation of purchases is the one that has been paid more attention to.

Hence, it is necessary for models aiming to explain consumers' motivations, as well as the consumption behaviours, that they cause, to be designed in such a way that they properly account for the overall value of the experience of consumption (Babin et al., 1994; Titus and Everett, 1995); this implies to jointly consider both utilitarian and hedonic benefits. Their only purpose should not be necessarily the explanation of purchase (see, as e.g., Bloch et al., 1989; Hirschman, 1980; Holbrook and Hirschman, 1982).

If we focus the previous reasoning on the electronic markets based on the web, it should be considered that there are some specific characteristics associated to this new exchanging context which favour the development of behaviours with hedonic orientations (Childers et al., 2001; McMeekin et al., 2000). Therefore, the necessary holistic consideration of the experience of consumption becomes essential. This has been the underlying philosophy followed to design the consumption motivational model previously shown in Figure 1.

\subsection{Consumption motivations on the web: a justification of its meta-dimensional division}

\subsubsection{Background}

In general terms, motivations are linked to those stimuli and impulses, conscious or unconscious, which lead an individual to reduce a state of mental strain originated by one or several unsatisfied needs (Schiffman and Kanuk, 1997). Thus, the study of motivations is necessary to explain the individuals' behavioural factors. In this respect, Pieters (1993) notes that motivations are the highest level component in the hierarchy of aspects that defines every behaviour, owing to the fact that they represent the objectives or benefits which an individual aims to achieve by means of his or her actions.

With regard to the existing categories of motivations, one of the most widely accepted approaches in social psychology - hence valid for marketing - is that which distinguishes the following categories.

- Intrinsic motivations, defined by Malone and Lepper (1987) in terms of what people do without external inducement, that is, motivations based mainly on practising a behaviour for no reward other than the interest and enjoyment that accompanies it. Thus, it is usually associated with perceived satisfaction for developing that behaviour in itself.

- Extrinsic motivations, those activities in which individuals engage to obtain some benefits, different to those provided by the development of such activities in themselves. Therfore, this category is associated with perceived usefulness for developing certain behaviours (Eiser, 1986; Teo et al., 1999; Teo, 2001). 
These are the kind of motivations that causes most of human behaviours (Csikszentmihalyi and Nakamura, 1989).

Likewise, with the aim of being more exhaustive, we present some other categories whose use for explaining consumer behaviour in final markets has been defended by several authors. These are the following.

- One of the most popular categories is that of Sheth (1983), who focused on explaining consumers' choices and purchases in physical markets. He distinguishes two types of motivations:

- functional, related to tangible attributes like convenience, variety of selection, quality of merchandising, price, availability of information, establishment's proximity, etc.

- $\quad$ non functional, related to intangible attributes.

In this sense, Sheth left out some questions directly associated with the retailer (as for example image and reputation), since he highlights that the most relevant aspects are the consumers' stimuli aiming to satisfy their social and emotional needs and desires, such as interacting with people, searching new and interesting shopping experiences, etc. (Eastlick and Feinberg, 1999).

- The categorisation presented by Bellenger and Korgaonkar (1980) distinguishes between two types of consumers considering that their shopping orientations might be

- $\quad$ purely economic, therefore only focused on achieving efficiency in the decision making

- recreational, therefore only focused on achieving pleasant shopping experiences (Fenech and O'Cass, 2001).

- A third classification also distinguishes between two types of shopping motivations:

- rational, related to driving the behaviour to select those alternatives which produce a higher economic utility

- emotional, related to searching personal and subjective objectives (Schiffman and Kanuk, 1997).

- Likewise, Solomon (1997) differentiates two groups of motivations regarding the kind of need that they satisfy:

- $\quad$ utilitarian, associated with behaviours aiming to look for functional or practical benefits

- hedonic, related to consumers' emotional answers which pursue new and pleasant shopping experiences.

Therefore, considering the previous review, and leaving apart some details that may be argued to differentiate each of the categorisations, it could be concluded that motivations which drive consumers' behaviour are: (1) functional or utilitarian, so driven by objective and economic criteria, also related to the extrinsic ones; vs. (2) non functional, emotional or hedonic, also related to the intrinsic ones. 


\subsubsection{Consumption motivations on the web}

Although most of the studies, which support the above categorisations do not belong to the research trend of consumer behaviour in electronic markets, we think that these models can easily be applied to this field. There has been a clear tendency to formally distinguish these categories making use of the terms utilitarian vs. hedonic (see, for example, Childers et al., 2001; Hammond et al., 1998; Hoffman and Novak, 1996; Wolfinbarger and Gilly, 2001). We have followed this notation in our model.

Apart from that, we should stress the fact that this duality just noted in consumption motivations does not necessarily imply that there is independence between both types of motivations. In other words, a consumption experience on the web may not only be driven by seeking utilitarian or hedonic benefits; i.e., with no interaction between them. On the contrary, there may be a relation of dependence and interchange between both meta-dimensions when motivating an individual to act. However, it is reasonable to say that, though such a relation may exist, in general, it is usually weak and there is often a dominant meta-dimension (see Babin et al., 1994; Eiser, 1986).

Proposition 1: Seeking utilitarian (hedonic) benefits in a consumption experience on the web does not exclude seeking hedonic (utilitarian) benefits. Both meta-dimensions may coexist, though there should be a dominant meta-dimension which initially defines the online behaviour orientation.

\subsection{Consumption behaviours on the web}

Several studies that focused on consumer behaviour in the internet have identified two broad categories of behaviours on the web, which can be associated to certain motivations or benefits sought in online shopping: goal-directed vs. experiential behaviours (Hammond et al., 1998; Hoffman and Novak, 1996, 1997; Novak et al., 2000; Wolfinbarger and Gilly, 2001). The former are driven by a specific shopping goal, while the latter are more spontaneous and exploratory, seeking for pleasant and funny consumption experiences.

\subsubsection{Goal-directed behaviour}

Online behaviours driven by certain shopping objectives are characterised by the consumer developing the online search (navigational) process with an epistemic strategic orientation (Titus and Everett, 1995). In other words, search patterns are clearly directed towards solving a decision problem (Janiszewski, 1998; Moe, 2001). Therefore, they are a consequence of several rational impulses aiming to select the best choice; i.e., there are underlying motivations that were previously related to the utilitarian meta-dimension. This type of online behaviour are associated with those consumers who use the web as a means to solve a decision problem, therefore it involves what is usually known as prepurchase search (Hoffman and Novak, 1996).

Proposition 2: Consumers who use the web to solve certain decision problem are driven by utilitarian motivations. Consequently, their navigation processes will be predominantly goal-directed. 


\subsubsection{Experiential behaviour}

Experiential behaviours on the web are a consequence of consumers' impulses aiming to simply get pleasant consumption experiences. There is no immediate decision problem to be solved driving the process of navigation. Consumers developing experiential behaviour are characterised by practising an ongoing search process (Hoffman and Novak, 1996). So unlike the precedent case, they are not directed by any previous shopping goal (Janiszewski, 1998; Moe, 2001). Hence, there are subjacent motivations which were associated with the hedonic meta-dimension.

Proposition 3: Consumers who use the web for hedonic purposes are not constrained by an immediate decision problem. Consequently, their navigation processes will be predominantly experiential.

\subsubsection{Relation between both online behaviour orientations}

The relation between motivation and behaviour seems obvious. Thus, in a similar way to the relation theoretically posed between the utilitarian and hedonic meta-dimensions, it can be easily concluded that consumers can also develop multi-purpose consumption processes on the web. Moreover, navigational strategies - i.e., behaviour orientations - on the web can be even modified while the online consumption experience is being developed. This reasoning is based on an adaptation of the reflections of several authors to the electronic market context (Bloch et al., 1989; Titus and Everett, 1995).

Proposition 4: There may be a relation between the consumer's behaviour/navigational orientations on the web, if this consumer is being simultaneously driven by utilitarian and hedonic consumption motivations. However, there should be a dominant orientation when starting the process of navigation as a consequence of the differences in the intensity of initial motivations, which determine, at first, how the consumer will orientate such process.

\subsubsection{The optimum stimulation level - flow state partnership: its influence in the behaviour orientations on the web}

In order to better understand consumers' process of navigation it is necessary to also consider the plausible influences of their desired and experienced mental stimulation states, inasmuch as they can originate different types of online behaviour/orientation on the web. This has been the main reason for including these psychological concepts in our model.

A crucial concept is that of flow state, which has been recently imported from motivational psychology and successfully adapted to explain consumer behaviour phenomena on the web (see, for example, Hoffman and Novak, 1996; Korzaan, 2003; Luna et al., 2002; Novak et al., 2000, 2003). Flow state is defined as "the process of optimal experience" or the mental state that individuals sometimes experience when they are deeply immersed in certain events, objects or activities (Csikszentmihalyi, 1975, 1977). Csikszentmihalyi (1990, p.3) makes use of the following paragraph to intuitively exemplify it. 
It is what the sailor holding a tight course feels when the wind whips through her hair, when the boat lunges through the waves like a colt-sails, hull, wind, and sea humming a harmony that vibrates in the sailor's veins.

This concept has been adapted to the web environment. Flow state is achieved when the consumer is so deeply involved in the process of navigation on the web" that "nothing else seems to matter" (Hoffman and Novak, 1996, p.57). In this respect, Novak et al. (2000, p.24) define the consumer's flow state on the web by the following terms:

\begin{abstract}
Concentration on the navigation experience is so intense that there is little attention left to consider anything else, and consequently other events occurring in the consumer's surrounding physical environment lose significance. Self-consciousness disappears, the consumer's sense of time becomes distorted, and the state of mind arising [...] is extremely gratifying.
\end{abstract}

Therefore, the flow state represents a mental state experienced by an individual during the process of navigation. This state determines the consumer's strategy of navigation - i.e., the behaviour orientation - and it may even cause an alternation between both types of orientations while the online consumption experience is being developed. ${ }^{3}$ However, there has been a tendency to relate this state of mind to the development of experiential behaviours (Hoffman and Novak, 1996; Korzaan, 2003). Novak et al. (2000) found that consumer's consumption experiences on the web were positively related to using this medium for hedonic purposes, though negatively related to activities implying an obligation; i.e., those involving a more epistemic orientation. This fact suggests that during the process of navigation it is more likely for consumers to achieve flow when developing recreational activities than when navigating to solve a situational decision problem.

Furthermore, Novak et al. (2003) recently noted, on the one hand, which flow state can influence both types of behaviours, though it is more reasonable for the intensity of the association to be higher with experiential behaviours. On the other hand, this state of mind can be bidimensional; i.e., a consumer could experience both utilitarian and hedonic flow states.

Proposition 5: Consumers achieve flow state during both goal-directed and experiential processes of navigation. However, the state of mind achieved will exert an influence on the behaviour orientation during the time of the consumption experience on the web. This factor should have a more intense influence with experiential behaviours than with goal-directed behaviours.

Proposition 6: Higher flow states will increase the probability that consumers modify their initial orientation of navigation, if epistemic, towards experiential behaviours, or to maintain it, if the initial orientation is hedonic.

The concept of optimum stimulation level $(O S L)$ represents the degree of sensory stimulation that an individual regards as adequate for himself. So, individuals tend to search for experiences that make them experience such desired level of stimulation. In this sense, the fact that human behaviour is often motivated to achieve certain satisfactory levels of stimulation has been analysed by motivational psychology. The essential idea of this motivational approach is that when individuals feel that they have not achieved such desired levels of stimulation, then they tend to develop exploratory behaviours with the aim of fulfilling that mental state by increasing their sensory stimulation (Steenkamp and Baumgartner, 1992; Steenkamp and Burgess, 2002). 
This fact can be more rigorously argued if we take into account that the difference between an individual's OSL and his/her degree of sensory stimulation really experienced is defined by the concept need of stimulation (NST) (Steenkamp et al., 1996). Thus, when NST is positive, the individual tends to perform actions to increase his experienced stimulation. On the contrary, when it is negative, the individual tends to diminish it (Parker and Tavassoli, 2000). Therefore, people will get the highest level of psychological pleasure when their experienced sensorial stimulation equals their OSL. If we adapt the previous reasoning to the electronic market context, a consumer will experience a state of optimal pleasure when the stimuli received during the process of navigation equals his/her OSL.

Considering the above, we have adapted Wundt's (1893) inverted U-shaped curve, which relates the intensity of the stimulation achieved by an individual with the level of experienced pleasure, with the aim of showing the relation between the concept of OSL and exploratory behaviours on the web (see Figure 2). Likewise, we have considered additional remarks of Parker and Tavassoli (2000, p.36).

Figure 2 Relationship between consumers' OSL and the development of exploratory behaviours on the web

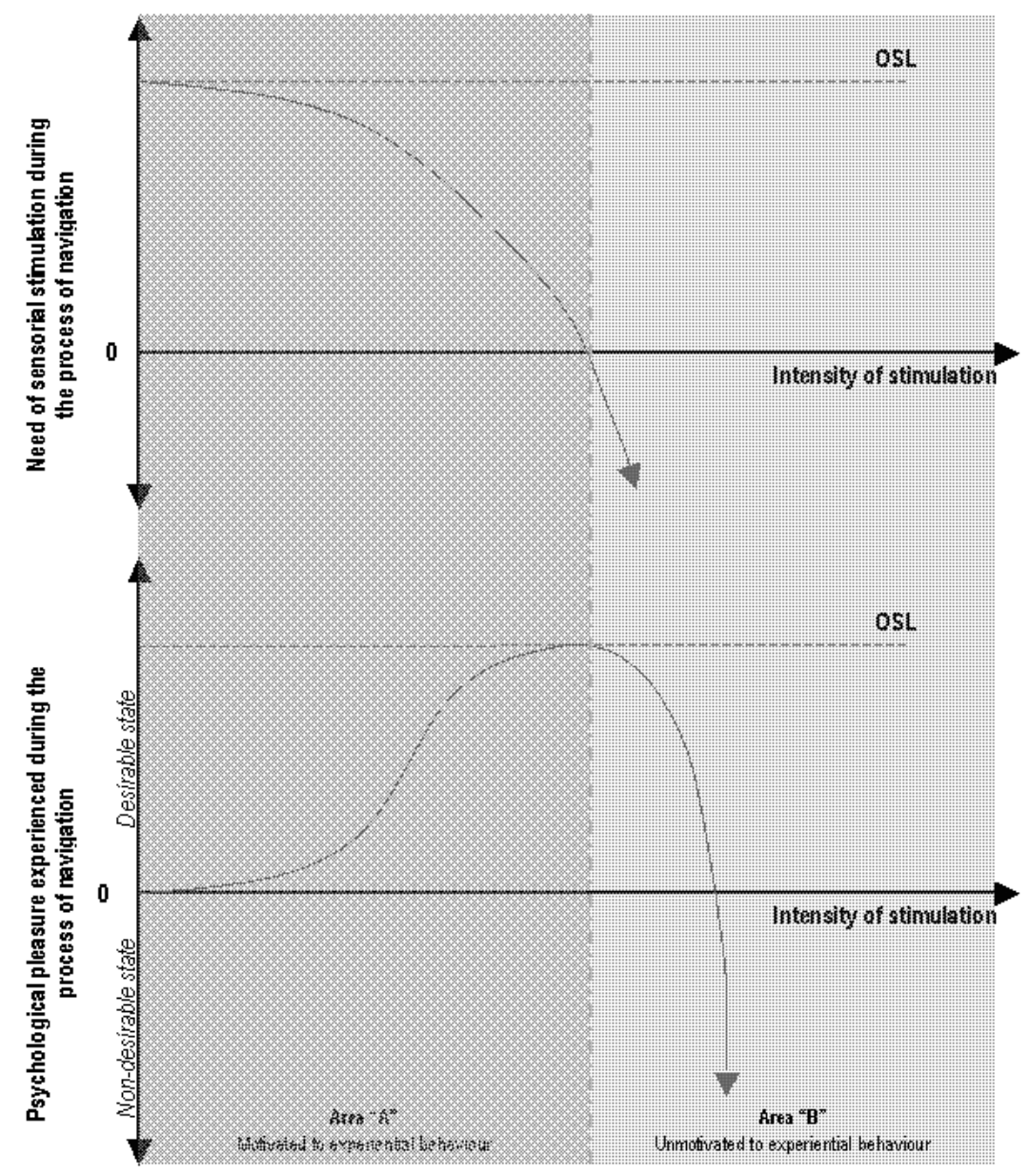


Among several of the interpretations that can be derived from the figure above, we highlight that it is expected that those consumers whose OSL are higher will tend to develop exploratory processes of navigation on the web; i.e., searching for positive psychological stimuli. This type of online behaviour will be maintained until their experienced stimulation states, caused by such processes of navigation, get closer or equal their OSL (Area A). Beyond this point (Area B), an increase in the intensity of the stimuli would saturate the consumer, so he or she would feel unmotivated to keep such orientation in the process of navigation.

Proposition 7: The higher the consumer's OSL, the higher his tendency to develop exploratory behaviours on the web.

Apart from the above remarks, the OSL also plays an important role in determining the state of mind - i.e., flow - which a consumer achieves during the process of navigation on the web. The web is characterised by providing high levels of sensory stimulation, especially visual stimuli, so it is a really interesting device for those consumers with high OSLs, tough it may have negative effects on others with lower OSL (Hoffman and Novak, 1996). Therefore, it is plausible to think that consumers with high OSLs will present higher levels of implication in searching for consumption experiences which satisfy their desired psychological stimulation level. There will be a higher probability for them to be more focused on such process of navigation.

Proposition 8: The higher the consumer's OSL, the higher the probability for him to be more concentrated in the process of navigation. In other words, the probability of experiencing flow will be higher.

\subsection{Buying orientation during the consumption experience}

In this section, we analyse the influence, which the online consumption behaviour orientation exerts on the possible output of such behaviour; i.e., purchase or no purchase. In the conceptual model, with the aim of reducing its components, we have only considered the tendency in which the consumption behaviours developed on the web finish with a purchase, so the non purchase option will not be explicitly accounted for.

As we noted in Section 3.2, goal-directed behaviours are characterised by being produced as a consequence of an immediate decision problem which needs to be solved. In this case, the web is used with utilitarian purposes, so it is more likely that this type of behaviours - associated with high situational involvements (Hoffman and Novak, 1996) - finish with a purchase if compared with experiential behaviours. For this latter case, the processes of navigation rather aim to obtain information with regard to certain product classes or services - those with which consumers present high and enduring involvement levels (Hoffman and Novak, 1996) - or to obtain benefits closely related to hedonic aspects of consumption phenomena (Bloch et al., 1989). According to Hirschman (1980), consumers' buying experiences with experiential consumption orientation on the web will be probably of a vicarious type rather than of a real type.

Nevertheless, it should be noted that the previous reasoning does not imply that an experiential behaviour on the web cannot be concluded with an online purchase. In this sense, a consumer could make an impulsive purchase with the aim of obtaining certain hedonic - sensory stimulation - benefits (see, for example, Baumgartner and 
Steenkamp, 1996; Holbrook and Hirchsman, 1982). However, this would be an unusual case.

Proposition 9: The processes of navigation developed by consumers with goal-directed purposes on the web will have a higher probability to conclude with an electronic transaction than others with experiential strategies.

\section{Concluding remarks and final reflections}

A holistic approach has been used to analyse consumption motivations on the web. This makes necessary a broad analysis of consumption experience, so the explanation of online purchasing was not our main objective. Indeed, we have focused on consumption motivations rather than on buying motivations; this latter aspect represents a particular instance of the consumption phenomenon.

However, the transcendence of studying the consumers' buying behaviour on the web cannot be doubted, especially if we take into account that the volume of commercial transactions is the main factor which runs the future of the majority of online businesses. In any case, keeping the orientation of this paper, that does not imply that websites should be designed with the only purpose of stimulating purchases, but they should offer pleasant consumption experiences, also making purchases lighter.

Likewise, though the orientation of this paper has been theoretical in essence, some academic and managerial implications for firms focused on $\mathrm{B} 2 \mathrm{C}$ may be extracted.

\subsection{Academic reflections}

If the theoretical framework supporting our model is taken into consideration, we obtain a logical sequence which explains online behaviours based on consumption motivations: (1) dimensions of motivations $\rightarrow$ (2) meta-dimensions $\rightarrow$ (3) behaviour tendencies $\rightarrow$ (4) output of the behaviour. In this respect, several issues have been considered.

Firstly, consumers' navigational processes have a dominant orientation, either utilitarian or hedonic, which will condition the type of behaviour developed; i.e., goal-directed or exploratory. This orientation not only differs depending on the consumer, but it may also vary for a single consumer depending on the time and circumstances in which his/her navigation process is being developed. Consequently, although it is difficult for models to graphically depict dynamism in consumers' behaviours, it can be assumed that, regardless of the initial orientation driving the process of navigation, such orientation may change during the process. In this sense, the interactive nature of the process originates certain stimuli which can divert the consumer from his or her initial orientation. An example of this would be unsolicited stimuli such as the additional information which is sometimes provided by recommendation systems.

Secondly, apart from the concepts associated with the above sequence, we have analysed the possible effects of the optimal stimulation level (OSL) and flow state on consumers' navigation orientation. In this regard, the following facts have been taken into account. 
- Consumers, independent of the type of behaviour they develop, may experience levels of flow state. However, it seems reasonable that such state will be more often associated with exploratory behaviours than with directed behaviours. Consequently, the higher the flow state achieved by the consumer, the higher the probability of reinforcing their exploratory orientation (if this was the initial orientation) or of modifying their orientation if it was initially goal-directed.

- The level of flow state experienced by a consumer during the process of navigation will be conditioned by the OSL or, in other words, by the desired stimulation level. Similarly, the higher the OSL, the higher the probability of searching for a real sensory stimulation state. For this reason, we believe that consumers with high OSLs will show a greater tendency to develop exploratory navigation behaviours.

\subsection{Managerial reflections}

We think that web businesses should focus on offering consumption experiences which match the objectives aimed at by their clients. To the extent to which online firms are able to satisfy this requirement, the number of visits to their websites will increase accordingly.

Consumption experiences are not conditioned only by the design of a website which facilitates purchases. There are other benefits sought by consumers, more closely related to the individual's hedonic aspects, such as sensory stimuli and gratifying experiences, which should receive enough attention.

Additionally, businesses should not classify their clients according to the behaviour they usually develop in their websites, that is, a client can be driven by both utilitarian and hedonic motivations. In this regards, online firms must be aware of the fact that situational factors condition the prevalence of one type of motivation over the other. For this reason, the interaction environment should be as wide as to allow the consumers to satisfy their specific needs in every single consumption process.

Finally, websites should not exert any kind of pressure on those clients who have already made their decisions. That is, purchasing processes must be as clear and fast as possible, so as to make the client feel the transaction has been carried out successfully.

\subsection{Future research}

Since the approach presented in this paper has been a purely theoretical one, some relevant questions have not been addressed. We intend to do so in a future empirical work, in which we will carry out a qualitative study with the purpose of determining the dimensions stemming from the two meta-dimensions of consumption behaviours on the web included in our model. Subsequently, our conceptual model will be empirically validated. 


\section{References}

Alba, J., Lynch, J., Weitz, B., Janiszewski, C., Lutz, R., Sawyer, A. and Wood, S. (1997) 'Interactive home shopping: consumer, retailer, and manufacturer incentives to participate in electronic marketplaces', Journal of Marketing, Vol. 61, pp.38-53.

Babin, B., Darden, W. and Griffin, M. (1994) 'Work and/or fun: measuring hedonic and utilitarian shopping value', Journal of Consumer Research, March, Vol. 20, pp.644-656.

Balabanis, G. and Reynolds, N. (2001) 'Factors influencing online shopping and e-store benefits sought', Proceedings of the 30th EMAC Conference, Bergen, Norway.

Baumgartner, H. and Steenkamp, J.B.E.M. (1996) 'Exploratory consumer buying behavior: conceptualization and measurement', International Journal of Research in Marketing, Vol. 13, No. 2, pp.121-137.

Bellenger, D.N. and Korgaonkar, P.K. (1980) 'Profiling the recreational shopper', Journal of Retailing, Vol. 56, pp.77-92.

Bhuian, S.N. (2001) 'Factors determining consumer interest in catalogs: an examination in an emerging market', Journal of Marketing Channels, Vol. 8, Nos. 3-4, pp.65-83.

Bloch, P., Ridway, N. and Sherrel, D. (1989) 'Extending the concept of shopping: an investigation of browsing activity', Journal of the Academy of Marketing Science, Vol. 17, No. 1, pp.13-21.

Childers, T., Carr, C., Peck, J. and Carson, S. (2001) 'Hedonic and utilitarian motivations for online retail shopping behaviour', Journal of Retailing, Vol. 77, pp.511-535.

Csikszentmihalyi, M. (1975) 'Play and intrinsic rewards', Journal of Humanistic Psychology, Vol. 15, No. 3, pp.41-63.

Csikszentmihalyi, M. (1977) Beyond Boredom and Anxiety, 2nd ed., Jossey-Bass, San Francisco.

Csikszentmihalyi, M. (1990) Flow the Psychology of Optimal Experience, Harper and Row, New York.

Csikszentmihalyi, M. and Nakamura, J. (1989) 'The dynamics of intrinsic motivation: a study of adolescents', in Ames, C. and Ames, R. (Eds.): Research on Motivation in Education, Academic Press, New York, Vol. 3, pp.45-71

Degeratu, A., Rangaswamy, A. and Wu, J. (2000) 'Consumer choice behaviour in online and traditional supermarkets: the effects of brand name, price, and other search attributes', International Journal of Research in Marketing, No. 17, pp.55-78.

Dickson, P. (2000) 'Understanding the trade winds: the global evolution of production, consumption, and the internet', Journal of Consumer Research, Vol. 27, pp.115-122.

Donthu, N. and Gilliland, D. (1996) 'Observations: the infomercial shopper', Journal of Advertising Research, March-April, pp.69-76.

Eastlick, M.A. and Feinberg, R.A. (1999) 'Shopping motives for mail catalog shopping', Journal of Business Research, Vol. 45, pp.281-290.

Eiser, J.R. (1986) Social Psychology. Attitudes, Cognition and Social Behaviour, Cambridge University Press, Cambridge, UK.

Ernst and Young, L.L.P. (2000) Global Online Retailing, Available at http://www.ey.com/

Ernst and Young, L.L.P. (2001) Global Online Retailing, Available at http://www.ey.com/

Fellenstein, C. and Wood, R. (2001) 'E-commerce. Explorando negocios y sociedades virtuales', Prentice-Hall, Buenos Aires, Argentina.

Fenech, T. and O'Cass, A. (2001) 'Internet users' adoption of web retailing: user and product dimensions', Journal of Product and Brand Management, Vol. 10, No. 6, pp.361-381.

Hamill, J. and Ennis, S. (1999) 'The Internet: the direct route to growth and development', in Baker, M.J. (Ed.): The Marketing Book (Fourth Edition), Butterworth-Heinemann, Oxford, pp.693-705.

Hamill, J. and Gregory, K. (1997) 'Internet marketing in the internationalisation of UK SMEs', Journal of Marketing Management, Vol. 13, pp.9-28. 
Hammond, K., McWilliam, G. and Narholz, A. (1998) 'Fun and work on the web: differences in attitudes between novices and experienced users', Advances in Consumer Research, Vol. 25, pp.372-378.

Hirschman, E. (1980). 'Innovativeness, novelty seeking, and consumer creativity', Journal of Consumer Research, Vol. 7, December, pp.283-295.

Hoffman, D. and Novak, T. (1996) 'Marketing in hypermedia computer-mediated environments: conceptual foundations', Journal of Marketing, Vol. 60, July, pp.50-68.

Hoffman, D. and Novak, T. (1997) 'A new paradigm for electronic commerce', The Information Society, No. 13, (special issue in electronic commerce).

Holbrook, M. and Hirschman, E. (1982) 'The experiential aspects of consumption: consumer fantasies, feelings, and fun', Journal of Consumer Research, Vol. 9, September, pp.132-140.

Janiszewski, C. (1998) 'The influence of display characteristics on visual exploratory search behavior', Journal of Consumer Research, Vol. 25, No. 3, pp.290-301.

Jevons, C. and Gabbott, M. (2000) 'Trust, brand equity and brand reallity in internet business relationships: an interdisciplinary approach', Journal of Marketing Management, Vol. 16, pp.619-634.

John, G., Weiss, A., Tappen, D., Tappen, J. and Dutta, S. (1999) 'Marketing in technology-intensive markets: toward a conceptual framework', Journal of Marketing, Vol. 63 (special issue), pp.78-91.

Jones, J. and Vijayasarathy, L. (1998) 'Internet consumer catalogue shopping: findings from an exploratory study and directions for future research', Internet Research: Electronic Networking Applications and Policy, Vol. 8, No. 4, pp.322-330.

Korgaonkar, P. and Wolin, L. (1999) 'A multivariate analysis of web usage', Journal of Advertising Research, March-April, pp.53-68.

Korzaan, M.L. (2003) 'Going with the flow: predicting online purchase intentions', Journal of Computer Information Systems, Summer, pp.25-31.

Leverick, F., Littler, D., Wilson, D. and Bruce, M. (1997) 'The role of IT in the reshaping of marketing', Journal of Marketing Practice: Applied Marketing Science, Vol. 3, No. 2, pp.87-106.

Lilien, G.L., Kotler, P. and Moorthy, K.S. (1992) Marketing Models, Prentice-Hall International Edition, London, UK.

Luna, D., Peracchio, L.A. and de Juan, M.D. (2002) 'Cross-cultural and cognitive aspects of website navigation', Journal of the Academy of Marketing Science, Vol. 30, No. 4, pp.397-410.

Malone, T. and Lepper, M. (1987) 'Making learning fun: a taxonomy of intrinsic motivations of learning', in Snow, R.E. and Farr, M.J. (Eds.): Aptitude, Learning, and Instruction, Conative and Affective Process Analyses, Lawrence Erlbaum, Hillsdale, NJ, Vol. 3, pp.223-253.

McMeekin, A., Miles, I., Roy, A. and Rutter, J. (2000) 'Clicks and mortar: the new store fronts', The Retail E-Commerce Task Force of the Retail and Consumer Services Foresight Panel, Available at http://www.foresight.gov.uk/.

Meeker, M. and Pearson, S. (1997) The Internet Retail Report, Morgan Stanley Dean Witter and Co., Available at http://www.msdw.com/.

Moe, W.W. (2001) Buying, Searching, or Browsing: Differentiating Between Online Shoppers Using in-store Navigational Clickstream, Working Paper, University of Texas, Austin.

Moorthy, K.S. (1993) 'Theoretical modeling in marketing', Journal of Marketing, Vol. 57, April, pp.92-106.

Novak, T., Hoffman, D. and Yung, Y. (2000) 'Measuring the customer experience in online environments: a structural modelling approach', Marketing Science, Vol. 19, No. 1 (Special issue on Marketing Science and the Internet), pp.22-42. 
Novak, T., Hoffman, D. and Duhachek, A. (2003) 'The influence of goal-directed and experiential activities on online flow experiences', Journal of Consumer Psychology, Vol. 13, Nos. 1-2, pp.3-16.

Parker, P.M. and Tavassoli, N.T. (2000) 'Homeostasis and consumer behavior across cultures', International Journal of Research in Marketing, Vol. 17, pp.33-53.

Peattie, K. and Peters, L. (1997) 'The marketing mix in the third age of computing', Marketing Intelligence and Planning, Vol. 15, No. 3, pp.142-150.

Pieters, R. (1993) 'A control view of the behaviour of consumers: turning the triangle', European Journal of Marketing, Vol. 27, No. 8, pp.17-27.

Reynolds, J. (2000) 'Ecommerce: a critical review', International Journal of Retail and Distribution Management, Vol. 28, No. 10, pp.417-444.

Rohm, A.J. and Swaminathan, V. (2004) 'A typology of online shoppers based on shopping motivations', Journal of Business Research, Vol. 57, No. 7, pp.748-757.

Rosen, K. and Howard, A. (2000) 'E-retail: Gold rush or fool's gold?', California Management Review, Vol. 42, No. 3, pp.72-100.

Schiffman, L. and Kanuk, L. (1997) Comportamiento Del Consumidor, $5^{\text {a }}$ ed., Prentice-Hall Hispanoamericana, Mexico.

Shern, S. and Crawford, F. (1999) The Second Annual Ernst and Young Internet Shopping Study, in Ernst and Young L.L.P, Available at http://www.ey.com/.

Sheth, J.N. (1983) 'An integrative theory of patronage preferente and behavior', en Darden, W.R. and Lusch, R.F. (Eds.): Patronage Behavior and Retail Management, Elsevier Science Publishing Co., Inc., New York, pp.9-28.

Sheth, J.N. and Sisodia, R.S. (1997) 'Consumer behaviour in the future', in Peterson, R.A. (Ed.) Electronic Marketing and the Consumer, Sage Publications, Inc. Thousand Oaks, CA.

Solomon, M.R. (1997) Comportamiento Del Consumidor, $3^{\text {a }}$ ed., Prentice-Hall Hispanoamericana, Mexico.

Steenkamp, J-B.E.M. and Baumgartner, H. (1992) 'The role of optimum stimulation level in exploratory consumer behavior', Journal of Consumer Research, Vol. 19, pp.434-488.

Steenkamp, J-B.E.M. and Baumgartner, H., Van der Wulp, E. (1996) 'The relationships among arousal potential, arousal and stimulus evaluation, and the moderating role of need for stimulation', International Journal of Research in Marketing, Vol. 13, pp.319-329.

Steenkamp, J-B.E.M. and Burgess, S.M. (2002) 'Optimum stimulation level and exploratory consumer behaviour in an emerging consumer market', International Journal of Research in Marketing, Vol. 19, pp.131-150.

Teo, T. (2001) 'Demographic and motivation variables associated with internet usage activities', Internet Research: Electronic Networking Applications and Policy, Vol. 11, No. 2, pp.125-137.

Teo, T., Lim, V. and Lai, R. (1999) 'Intrinsic and extrinsic motivation in Internet usage', Omega. The International Journal of Management Science, Vol. 27, pp.25-37.

Titus, P.A. and Everett, P.B. (1995) 'The consumer retail search process: a conceptual model and research agenda', Journal of the Academy of Marketing Science, Vol. 23, No. 2, pp.106-119.

Watson, R.T., Pitt, L.F., Berthon, P. and Zinkhan, G.M. (2002) 'U-commerce: expanding the universe of marketing', Journal of the Academy of Marketing Science, Vol. 30, Vol. 4, pp.333-347.

Windham, L. and Orton, K. (2000) The Soul of the New Consumer. The Attitudes, Behaviors and Preferences of E-Customers, Allworth Press, New York.

Wolfinbarger, M. and Gilly, M. (2001) 'Shopping online for freedom, control, and fun', California Management Review, Vol. 43, No. 2, pp.35-55.

Wundt, W.M. (1893) Grundzuge der Physiologischen Psychologie, Engelman, Leipzig. 


\section{Notes}

${ }^{1}$ The conceptual model has been graphically presented following a style of design similar to that used by structural equation modelling. In this sense, as it can be seen, there are three second-order constructs: the two meta-dimensions and the exploratory behaviour.

${ }^{2}$ Based on Novak et al. (2000), the concept of flow state in our model is related to the state experienced when developing navigational processes in general, that is, it is not related to the state which may be experienced in a specific web location (such as, for example, a corporation's website), although it could be adapted to this situation.

${ }^{3}$ A more detailed analysis of the influence of flow state in the behaviour developed on the web should be approached from an experiential point of view. This should consider aspects such as the individual's initial predisposition to behave in a certain way, the stimuli or characteristics associated with both utilitarian and hedonic aspects of the consumption experience, the flow state achieved and its influence in subsequent navigation behaviours, etc. Nevertheless, the relationship between flow state and developed behaviours has been analysed in static behaviour models - similar to that presented in this paper - which have not been able to include the dynamic aspects of navigation. 